\title{
Surface Perfluoroalkyl Chains Segregation: A Tool for Reducing Calcium Deposits in Medical Grade Poly(Methyl Methacrylate)
}

\author{
Baljit K. Ghatora1 ${ }^{*}$, Peter J. S. Foot ${ }^{1}$, Stephen J. Barton'1, Ravtej S.Thatti' ${ }^{1}$, Antonio Papagni2, \\ Luca Vaghi²
}

${ }^{1}$ Materials Research Centre, SEC Faculty, Kingston University, Surrey, UK

${ }^{2}$ Department of Materials Science, University of Milano-Bicocca, Milano, Italy

Email: *B.Ghatora@kingston.ac.uk

How to cite this paper: Ghatora, B.K., Foot, P.J.S., Barton, S.T., Thatti, R.S., Papagni, A. and Vaghi, L. (2017) Surface Perfluoroalkyl Chains Segregation: A Tool for Reducing Calcium Deposits in Medical Grade Poly(Methyl Methacrylate). Journal of Biomaterials and Nanobiotechnology, 8 , 176-187.

https://doi.org/10.4236/jbnb.2017.82012

Received: January 9, 2017

Accepted: April 27, 2017

Published: April 30, 2017

Copyright $\odot 2017$ by authors and Scientific Research Publishing Inc. This work is licensed under the Creative Commons Attribution International License (CC BY 4.0).

http://creativecommons.org/licenses/by/4.0/

\begin{abstract}
Intraocular lenses can be manufactured from a wide variety of polymers, but due to the lost cost associated with the use of Poly(methyl methacrylate) (PMMA), it is still the preferred material used in the developing countries. However, a major drawback to its use is the build-up of calcium containing deposits that are formed on the intraocular lens over a period of time. In an attempt to hinder this deposition, surface modification of medical grade PMMA has been carried out using perfluoroalkyl chain (1,2,4-trifluoro-3$\left(\mathrm{C}_{10} \mathrm{~F}_{21} \mathrm{CH}_{2} \mathrm{O}\right)-7-(\mathrm{N}, \mathrm{N})$-dimethylaminoacridine) segregation. The segregation was explored using a 1\% 1,2,4-trifluoro-3- $\left(\mathrm{C}_{10} \mathrm{~F}_{21} \mathrm{CH}_{2} \mathrm{O}\right)-7-(\mathrm{N}, \mathrm{N})$-dimethylaminoacridine in two methods: film casting and spin-coating, a thin film onto preformed PMMA discs. Both methods were compared against control PMMA to determine which method provided the best hindrance against calcium containing deposits when immersed in a simulated aqueous humour solution. Characterisation of the surface using scanning electron microscopy coupled with energy; dispersive $\mathrm{x}$-ray analysis indicated that the surface segregation of perfluoroalkyl chains had hindered calcification in both methods. This pleminary research shows promising results of employing perfluoroalkyl chains in the surface segregation of biomaterials that can be employed in intraocular lenses.
\end{abstract}

\section{Keywords}

Poly(Methyl Methacrylate) (PMMA), Perfluoroalkyl, Segregation, Medical Polymers, Wettability, Calcium Deposits

\section{Introduction}

Modification of polymer surfaces can be used to improve the performances of 
these materials and to pave the way to new technological applications. Wettability is one of the most important properties, which can be modified either both by altering the surface morphology or the surface chemistry. Fluorination of $\mathrm{C}-\mathrm{H}$ bonds at the surface of hydrophilic materials is a straightforward way to induce repellency toward water and oils [1] [2], thanks to the chemical inertness and the low coefficient of friction of C-F bonds. These surface induced properties have been already exploited in advanced technological applications such as protective clothing, stain-proof textiles [3], medical surgery and implants [4] [5] and marine coatings [6].

The surface modification is particularly appealing in the field of biomaterials, as the specific intrinsic bulk material properties are retained, while those of surfaces can be modified and debugged in order to enhance biocompatibility [7] [8] [9]. Intraocular lenses (IOLs) are used during cataract surgery to replace the opacified crystalline lens, and they can be made from a wide variety of polymeric materials. For example, acrylic-based polymers are routinely used in foldable IOLs that require only a small incision in the cornea for their insertion. However, due to their relative high costs, many developing countries are still using IOLs manufactured using the more economic poly(methyl methacrylate) (PMMA) [10] [11]. Nevertheless, one of the post-operative drawbacks of PMMA IOLs is opacification along the time, which occurs due to calcium containing deposits building-up on the surface of the IOL [12] [13] [14]. In these lenses, a surface modification that can reduce the calcium containing deposits is particularly attractive since it can contribute to keeping down costs and avoiding the associated trauma of repeat surgeries to remove the opacified/calcified IOL. Surface fluorination, by specific surface chemical reactions, has been routinely applied to biomaterial surfaces to increase the biocompatibility of organic materials with the human body [15], and recently researchers have assessed the use of direct surface fluorination IOL using plasma techniques employing elemental fluorine [16]. In this latter case, although the plasma fluorination treatment is very aggressive, both the wettability of PMMA surfaces and calcium containing deposits are sensibly reduced. Plasma fluorination is one of the many ways in which surfaces can be modified, and another modification method includes surface segregation. The natural tendency for surface segregation of molecules bearing perfluoroalkyl chains when dispersed in polymers can be exploited to improve the hydro- and lipophobicity of these materials. In IOLs, in addition to an improved hydro- and lypophobicity, the build-up of surface deposits should be sensibly hindered. Indeed the fluorinated surface acts as a barrier to diffusion and Chen et al. [17] have reported that fluorination of PMMA or fluorocarbon coatings on a PMMA surface led to a decrease in surface polarity, thus creating a more hydrophobic surface that would ideally hinder diffusion and surface deposits.

Surface perfluoroalkyl chains segregation studies have been recently reported where 1,2,3,4-tetrafluoro-7-perfluorodecylacridine [18] and 1,2,4-trifluoro-3$\left(\mathrm{C}_{10} \mathrm{~F}_{21} \mathrm{CH}_{2} \mathrm{O}\right)-7-(\mathrm{N}, \mathrm{N})$-dimethylaminoacridine [19] have been utilized as dopant 
of PMMA and 6,6-Nylon. Films and electro-spun fibres of these were prepared from suitable solvents and their surface properties analyzed in relation to dopant concentration over a period of time. The emission properties of these molecules [18] [20] were also exploited to follow their localization in the polymers. During the preparation of electro-spun fibres, a spontaneous surface segregation has been observed without resorting to a thermal annealing treatment. Excellent low water wettabilities (similar to that of Teflon) have been obtained even at low dopant concentration and on 6,6-Nylon this low wettability still remains after 2 months.

In this study we extend the used 1,2,4-trifluoro-3- $\left(\mathrm{C}_{10} \mathrm{~F}_{21} \mathrm{CH}_{2} \mathrm{O}\right)-7-(\mathrm{N}, \mathrm{N})$-dimethylaminoacridine (ACR) (Figure 1) to modify medical grade PMMA employed in manufacturing IOLs with the aim to analyse the surface properties in a simulated ocular aqueous humour solution.

Studies were carried out to test the various methods by which the PMMA can be modified to provide a barrier to diffusion and calcification. The investigation into whether the surface modification could be employed in PMMA fabricated intraocular lenses will be explored, with the intention to consider implementation within the final stages of manufacturing intraocular lenses.

\section{Experimental Details}

\subsection{Materials}

All the starting materials were purchased from Aldrich Chemical Co., Alfa Aesar or Fischer Scientific; or Fluorochem for fluorinated reagents. Solvents were of analytical grade and used as received. High molar mass medical-grade PMMA discs (2.5 mm thickness and $10 \mathrm{~mm}$ diameter) were used in this study.

\subsection{Method}

The 1,3,4-trifluoro-2- $\mathrm{C}_{10} \mathrm{~F}_{21} \mathrm{CH}_{2} \mathrm{O}-7$ - $(\mathrm{N}, \mathrm{N})$-dimethylaminoacridine (ACR) has been prepared by reacting the corresponding tetrafluoroacridine with the sodium salt of $1 \mathrm{H}, 1 \mathrm{H}$-perfluoroundecanol according to the protocol reported in the literature [19]. A 1\% (Acridine:PMMA) solution was prepared by adding ACR $(0.0022 \mathrm{~g})$ to dichloromethane (DCM) $(35 \mathrm{~mL})$ and stirred for $10 \mathrm{~min}$, after which a PMMA disc $(0.2307 \mathrm{~g})$ was added to the solution. After complete dissolution of the disc, the resulting solution (PMMA plus ACR) was used to prepare two different types of samples as indicated below. These samples have been investigated to determine which method was the most efficient in terms of perfluoroalkyl chain surface segregation. All analysis has been completed by com-

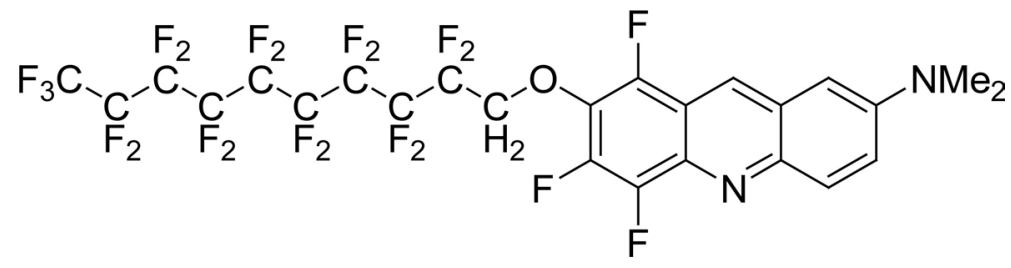

Figure 1. 1,2,4-Trifluoro-3- $\mathrm{C}_{10} \mathrm{~F}_{21} \mathrm{CH}_{2} \mathrm{O}-7-(\mathrm{N}, \mathrm{N})$-dimethylaminoacridine. 
paring the results with those obtained on an un-doped PMMA sample.

Method 1: a thin PMMA film doped with ACR. The prepared 1\% solution, from above $(20 \mathrm{~mL})$, was transferred into a small glass vial and left to dry under air flow for solvent evaporation to occur, until a thin, clear yellow film was formed coating the inside of the vial. The film was removed using boiling water and subsequently annealed in an oven at $100^{\circ} \mathrm{C}$ for 30 minutes.

Method 2: a thin PMMA film doped with ACR has been produced by spincoated technique onto preformed PMMA discs $(2.5 \mathrm{~mm}$ thickness and $10 \mathrm{~mm}$ diameter). A drop (approx. $25 \mu \mathrm{L}$ ) of the ACR and PMMA solution was spincoated onto one face of PMMA disc $(0.2240 \mathrm{~g})$ and annealed in the oven for 30 $\min$ at $100^{\circ} \mathrm{C}$.

\section{Simulated Eye Studies}

Simulated ocular aqueous humour solution (SAHS) was prepared using five Phosphate Buffered Saline (PBS) tablets (Fischer Scientific) dissolved in distilled water $(1 \mathrm{~L})$ at $35^{\circ} \mathrm{C}$. The following materials were then added: $\mathrm{NaCl}(7.1943 \mathrm{~g})$, $\mathrm{NaHCO}_{3}(1.6801 \mathrm{~g}), \mathrm{KCl}(0.2982 \mathrm{~g}), \mathrm{MgCl}_{2} \cdot 6 \mathrm{H}_{2} \mathrm{O}(0.1322 \mathrm{~g}), \mathrm{Na}_{3} \mathrm{PO}_{4}(0.16801 \mathrm{~g})$, $\mathrm{CaCl}_{2} \cdot 2 \mathrm{H}_{2} \mathrm{O}(0.1911 \mathrm{~g}), \mathrm{Na}_{2} \mathrm{SO}_{4}(0.1846 \mathrm{~g})$, urea $(0.3663 \mathrm{~g})$, glucose $(0.5044 \mathrm{~g})$, alanine $(0.0223 \mathrm{~g})$, serine $(0.0841 \mathrm{~g})$, valine $(0.0293 \mathrm{~g})$ (all from Sigma-Aldrich) and sodium lactate $(0.5043 \mathrm{~g})$ (Alfa Aesar). $1 \%$ sodium hyaluronate solution was prepared by dissolving sodium hyaluronate $(0.2500 \mathrm{~g})$ in $25 \mathrm{~mL}$ of PBS. $110 \mu \mathrm{L}$ of this was added to the solution of SAHS. $450 \mu \mathrm{L}$ of a $30 \%$ albumin solution was also added to the solution of SAHS using a pipette, and the solution was mixed thoroughly. The final SAHS obtained was then filtered using Whatman \#6 filter paper, the $\mathrm{pH}$ was adjusted to be between 6.8 and 7.0 with a few drops of hydrochloric acid $(1 \mathrm{M})$ and stored, until use, in the oven at $35^{\circ} \mathrm{C}$ [21].

The PMMA discs/films doped with ACR and PMMA un-doped discs were individually weighed prior to being immersed separately in SAHS $(20 \mathrm{~mL})$ and removed for analysis at staggered time points over a period of approximately 3 weeks. This time point was selected based upon then number of samples available. Prior to all analyses, superficial fluid was removed from sample surfaces by blotting them with filter paper.

\subsection{Bulk Property Analysis}

After removal from the SAHS, each sample was analysed gravimetrically using a 3 decimal place balance, and the weight after immersion was noted in order to calculate the gain/loss weight percentage $\mathrm{M}_{t}$ using the following equation (Equation (1)).

$$
M_{t}(\%)=\frac{M_{w}-M_{d}}{M_{d}} \times 100
$$

where $M_{d}$ is the initial mass of the sample prior to immersion in the SAHS, and $M_{w}$ is the mass of sample after immersion in SAHS.

\subsection{Surface Characterisation}

The samples were carefully mounted onto Scanning Electron Microscopy (SEM) 
slides, which were plated with gold. SEM images using a beam current of $1.5 \mathrm{nA}$ were specifically taken of those sample areas where materials seemed to be deposited. The discs were then analysed using energy dispersive $x$-ray analysis (EDX) (with a detection limit of $0.3 \mathrm{wt} \%-0.5 \mathrm{wt} \%$ ), and the peaks labelled on the spectra, including the expected $\mathrm{Au}$ (gold plating peak).

\section{Results and Discussion}

\subsection{Gravimetric Analysis}

The two batches of samples prepared by the methods above were analysed alongside control PMMA for increases/decreases in mass after immersion in SAHS. The results are shown in Table 1.

The gravimetric analysis was carried out over a period of 19 days ( $456 \mathrm{~h}$ ), and during this period the thin film and spin-coated samples immersed within the SAHS both exhibited an small initial \% increase in mass (Table 1). It is likely that this increase may have been caused by solvent damage from the DCM that was used during the dissolution process. During these processes it is likely that pores were created within the PMMA during the fast solvent evaporation process, this was evident from slightly cloudy appearance of the film. Once these pores are exposed to the SAHS these will result in an increase in mass from the pores filling up with SAHS [22]. The minor increase observed in the thin film could be ascribed to a better surface segregation of perfluoroalkyl chain all over the sample, while in spin-coated sample on one face of PMMA disc was treated. This is confirmed by the similar increase in mass of the ACR doped PMMA spin-coated on the preformed PMMA discs and the control PMMA disc. After $192 \mathrm{~h}$, as seen in Figure 2, the \% increase in mass of the spin-coated sample $(1.00 \%)$ is close to that of the control PMMA (1.20\% increase). The spin coated sample was only coated on one side, which resulted in the surface area of the un-coated area of the sample to be far greater than the coated. Therefore, the increase could be accounted for by the un-coated edges being exposed to the SAHS and subsequently causing greater diffusion of water from the SAHS into the PMMA.

The first state in Fickian diffusion, as studied by Crank [23], is due to water molecules from the environment migrating to the pores, voids and other free volume in the polymer to achieve concentration equilibrium. After this period it

Table 1. Gravimetric analysis of ACR doped PMMA and control un-doped PMMA.

\begin{tabular}{ccccccc}
\hline & \multicolumn{7}{c}{ \% change in Mass } \\
\hline Sample ID & 24 & 96 & 120 & 192 & 264 & 456 \\
Hours & Hours & Hours & Hours & Hours & Hours \\
\hline $\begin{array}{c}\text { Thin PMMA film doped with ACR } \\
\text { immersed in SAHS }\end{array}$ & 0.12 & 0.18 & 0.31 & 0.56 & -0.70 & -1.30 \\
$\begin{array}{c}\text { Thin PMMA film doped with ACR } \\
\text { spin-coated onto PMMA discs and } \\
\text { immersed in SAHS }\end{array}$ & 0.22 & 0.83 & 1.04 & 1.00 & 1.57 & 1.39 \\
$\begin{array}{c}\text { Control PMMA disc immersed in SAHS } \\
\text { PMm }\end{array}$ & 0.55 & 0.54 & 0.82 & 1.18 & 1.20 & 1.41 \\
\hline
\end{tabular}




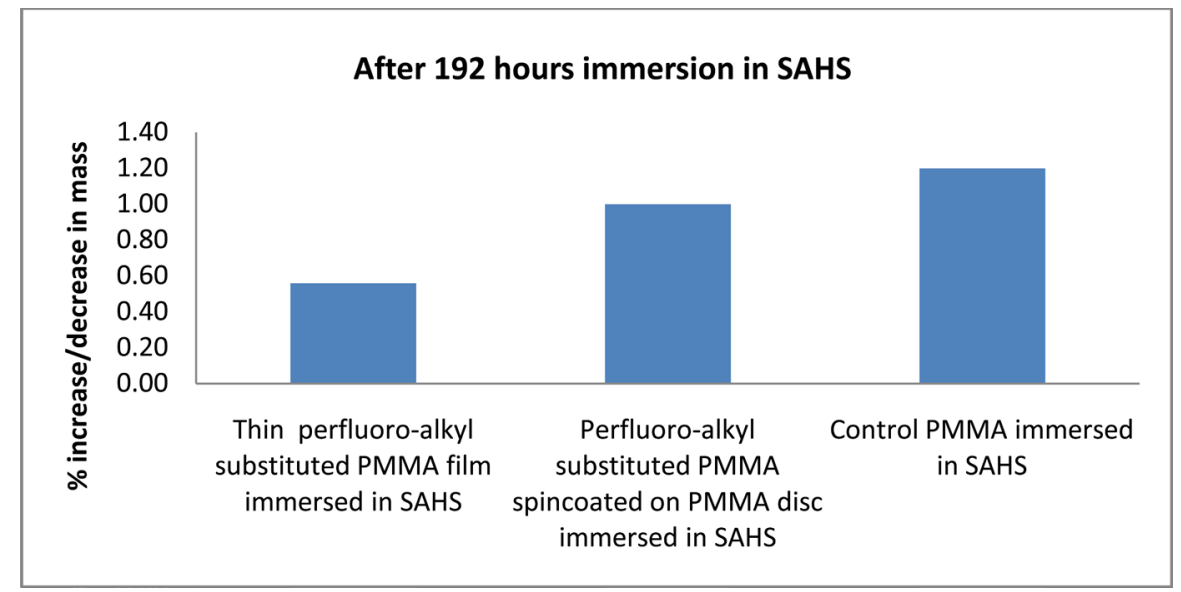

Figure 2. Comparison of samples immersed in SAHS after 192 hours.

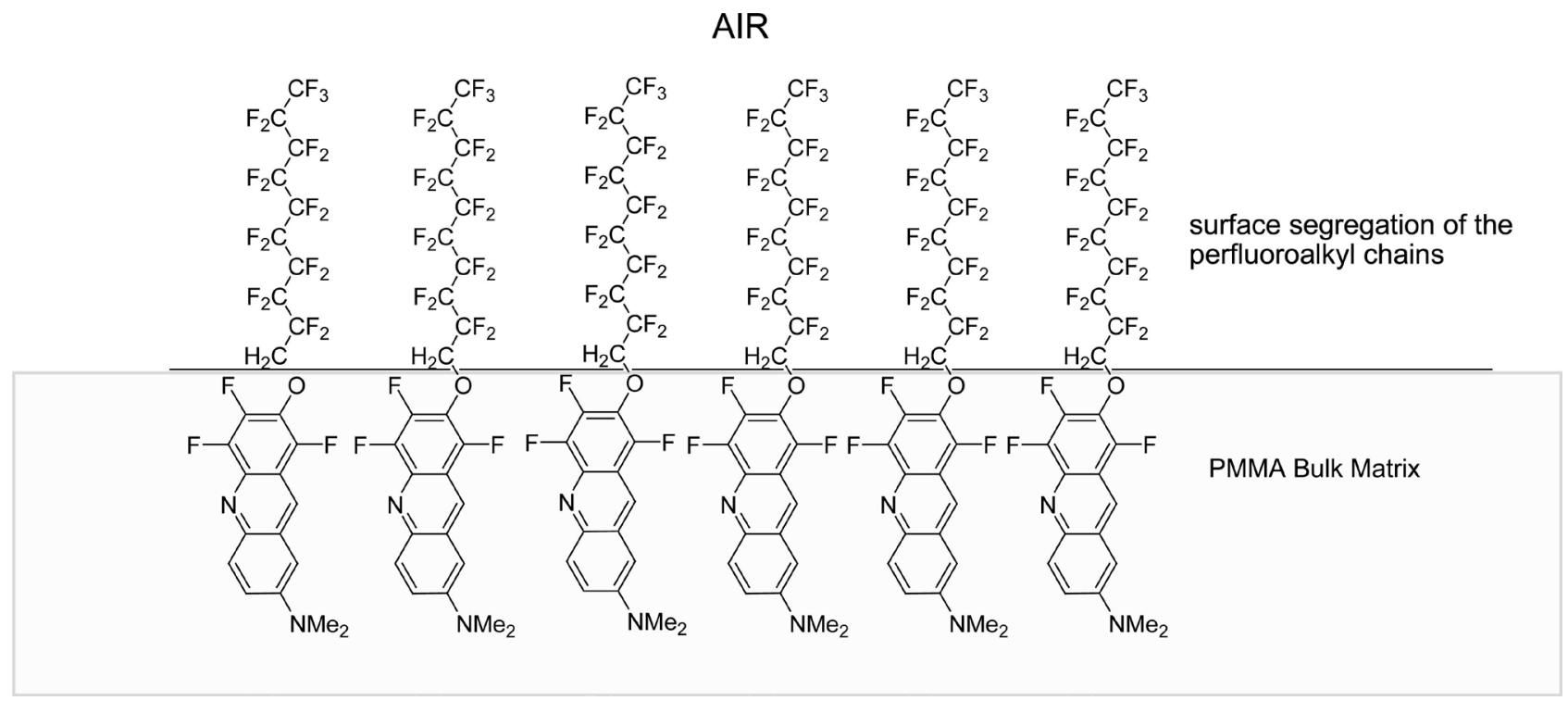

Figure 3. Diagrammatic representation of the surface segregation of PMMA doped with perfluoroalkyl substituted molecules.

is possible for desorption to occur, whereby any non-bonded water molecules diffuse out of the polymer matrix, which can be noted as a decrease in total mass. This decrease was calculated in the thin film PMMA sample doped with perfluoroalkyl-substituted system after being immersed in SAHS for 264 hours. Thanks to a higher segregation of perfluoroalkyl chains at the surface making it more hydrophobic surface, this likely hinders any further water molecules to absorb into the PMMA sample and consequently should limit the formation of calcium containing deposits on the surface. In addition, in the ACR-doped thin film samples, there would be a greater surface area that could hinder deposition than the spin-coated PMMA sample where only one side was coated and the edges were left un-coated. In Figure 3 is reported a schematic representation of perfluoroalkyl chains segregation on the PMMA surface.

\subsection{Surface Characterisation}

SEM images of all samples were collected after $456 \mathrm{~h}$ of immersion in the SAHS 
to enable the individuation of any deposition on the surface. Subsequently the EDX analysis allows the nature of atoms of both the polymeric matrix and the deposits onto the surface to be characterised. Figure 4 shows the SEM and EDX characterisation of the thin film ACR-doped PMMA after $456 \mathrm{~h}$ of immersion in SAHS. The film surface overall appears to be regular and smooth with very little evidences of deposition. There are some areas where deposits look more evident and the EDX analysis identifies that these contain only sodium ( $\mathrm{Na}$ ) and chlorine $(\mathrm{Cl})$. Thus the observed powder-like deposits on the surface are sodium chloride micro-crystals from the SAHS solution. These deposits, however, seem to play no role in the calcification of IOLs, as they are washed off after re-immersion.

The EDX analysis of the deposit-free part of the thin film PMMA surface (area A in Figure 4) shows the expected fluorine (F) peak along with peaks due to the carbon $(\mathrm{C})$ and oxygen $(\mathrm{O})$ from the PMMA material. The absence of calcium is an indication of the effectiveness of the fluorination in reducing calcification. The ACR-doped PMMA spin-coated on a PMMA disc analysed by SEM seems to show more powder-like deposits than the thin films (Figure 5). The corresponding EDX analyses of the areas A and B on the SEM image show that both areas are not deposits from SAHS deposits since only carbon, oxygen and fluorine atoms coming from PMMA and doping molecule are detected. The great difference in comparison with the ACR-doped thin film, is the higher fluorine signal and this could indicate a better surface segregation of perfluoralkyl chains in the spincoated films.

Upon comparison of the perfluoroalkyl-substituted PMMA samples against the control PMMA (Figure 6), it was evident that the surface segregation of perfluoroalkyl chains had hindered calcification. The control PMMA sample had deposits that appear to be more permanent on the surface; which will not be able to be washed off during replenishment of the aqueous humour in the eye. The corresponding EDX shows that these deposits contain calcium and sodium.

\section{Conclusions}

Surface modification is commonly used in industry to exploit the bulk property of a material; for example, petrol tanks are lined with a modified surface containing a fluorinated layer to hinder permeation and loss of petrol. The fluorinated layer acts as a barrier by making the surface more lipophobic, reducing the permeation of petrol. It was therefore, anticipated that, if fluorine was used as a surface modification on materials used to develop IOL's, the same properties could be employed in reducing calcification.

In this preliminary research, fluorination was carried out, exploiting the surface segregation of perfluoroalkyl chains in PMMA samples doped with perfluoroalkyl-substituted acridine; samples prepared by film casting or spin-coating showed better stability against calcium deposition with respect to control pristine PMMA. The surface-modified samples only underwent the formation of non-permanent deposits containing sodium chloride that could be 

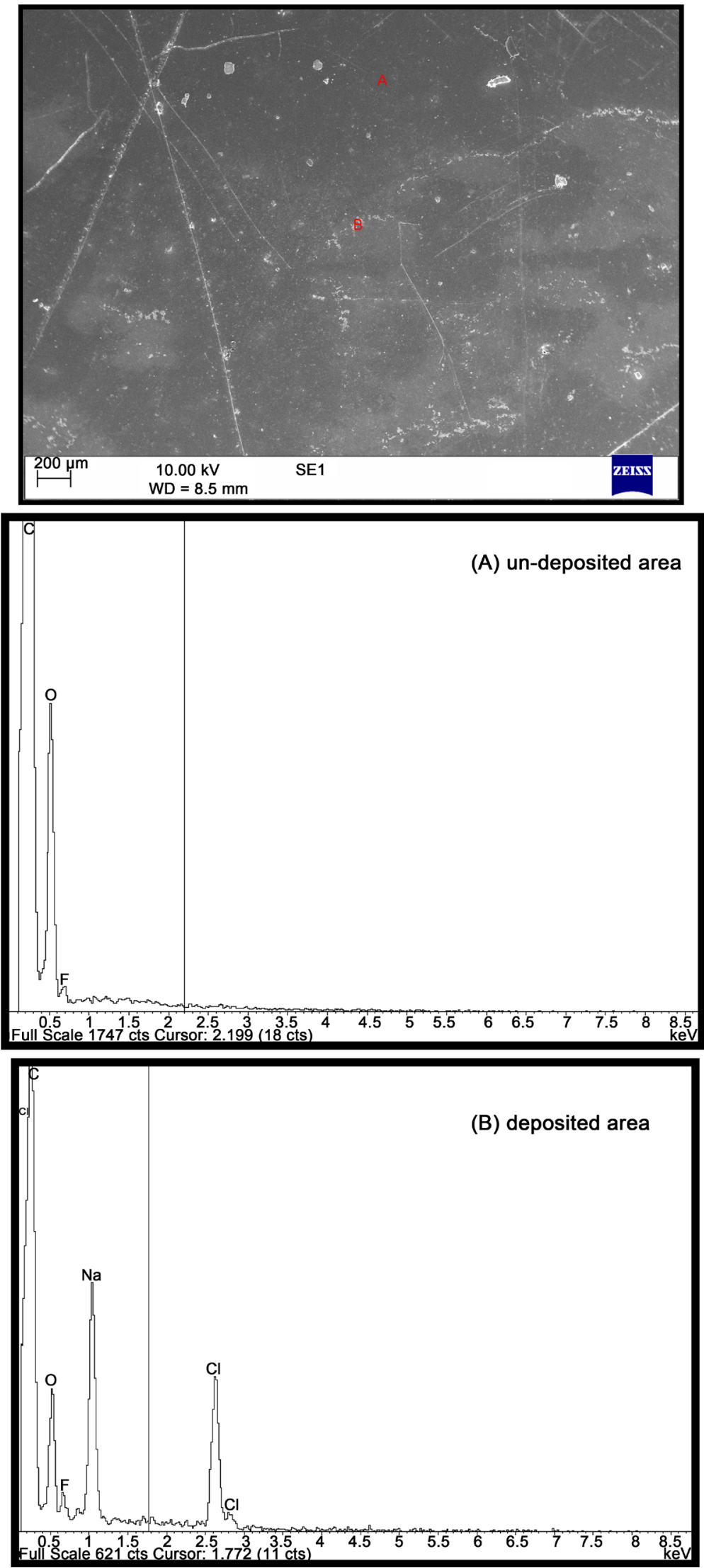

Figure 4. SEM image of a typical thin perfluoroalkyl substituted PMMA film immersed in SAHS for $456 \mathrm{~h}$, with corresponding EDXA data for (A) un-deposited area, (B) deposited area. 

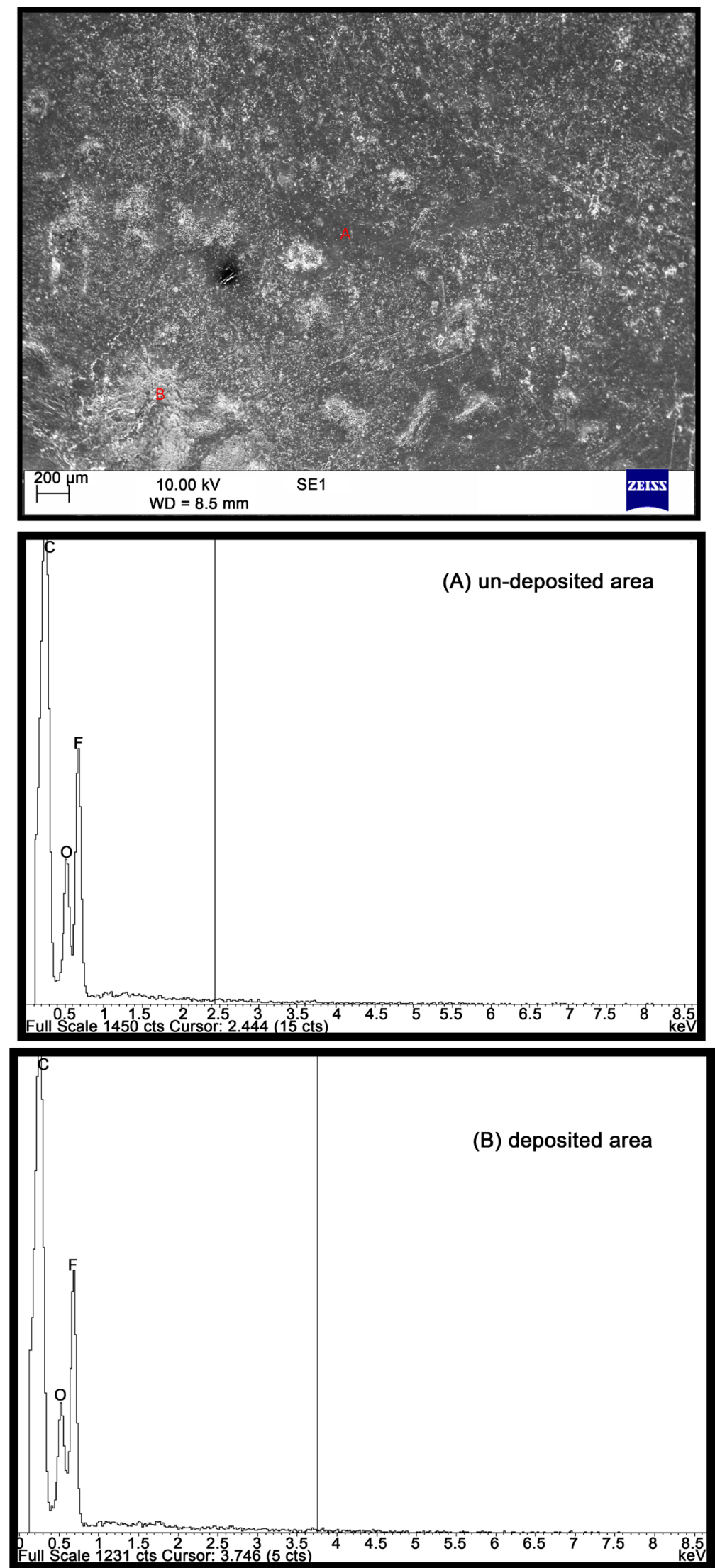

Figure 5. SEM image of perfluoroalkyl substituted PMMA spin-coated on PMMA disc immersed in SAHS for 456 hours, with corresponding EDXA for (A) un-deposited area, (B) deposited area. 

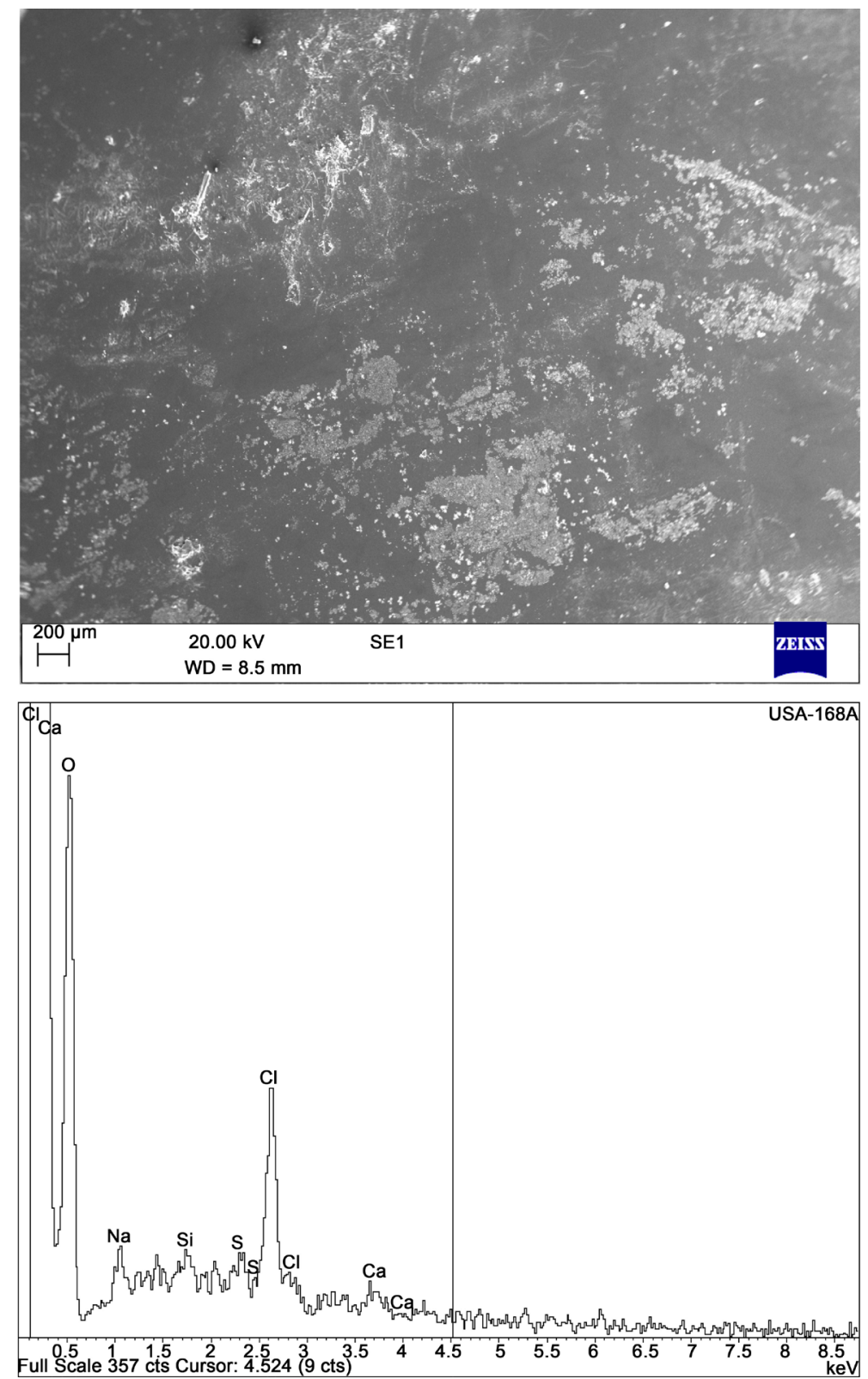

Figure 6. Control PMMA incubated in SAHS for $168 \mathrm{~h}$, with corresponding EDXA spectrum.

washed off during the replenishment of the aqueous humour while similar deposits were not observed in spin-coated PMMA samples. The initial studies carried out using the perfluoroalkyl-substituted PMMA incorporated into a thin film provided promising results in terms of inhibiting surface deposition. The results indicate that perfluoroalkyl chains in PMMA samples doped with perfluoroalkyl-substituted acridine when incorporated into intraocular lens themselves could be exploited to provide a repellent surface that hindered deposition. The results so far (in vitro) have indicated that when these modified samples are exposed to the aqueous humour, they can reduce, if not hinder deposition. This means that the lifetime of the intraocular lens could be improved. The full extent of the advantages that accompany the modification will only be fully understood 
after further analysis has been carried out.

\section{Funding}

This work was supported by the Royal Society of Chemistry Researcher Mobility Grant.

\section{References}

[1] Kissa, E. (1984) Soil Release Finishes. In: Sello, S.B. and Lewin, M., Eds., Handbook of Fibers Science and Technology, Marcel Dekker, New York, 142-210.

[2] Castelvetro, V., Francini, G., Ciardelli, G. and Ceccato, M. (2001) Evaluating Fluorinated Acrylic Latices as Textile Water and Oil Repellent Finishes. Textile Research Journal, 71, 399. https://doi.org/10.1177/004051750107100506

[3] Sargent, R.R. and Alexander, J.R. (1996) US Patent 5.560.992.

[4] Lee, S., Cho, J.S. and Cho, G.S. (1999) Antimicrobial and Blood Repellent Finishes for Cotton and Nonwoven Fabrics Based on Chitosan and Fluoropolymers. Textile Research Journal, 69, 104. https://doi.org/10.1177/004051759906900205

[5] Anderson, M.H., Lyons, C.S. and Wigness, B.D. (1985) US Patent 4.536.179.

[6] Honeychuck, R.V., Ho, T., Wynne, K.J. and Nissan, R.A. (1993) Preparation and Characterization of Polyurethanes Based on a Series of Fluorinated Diols. Chemistry of Materials, 5, 1299. https://doi.org/10.1021/cm00033a020

[7] Chu, P. (2007) Enhancement of Surface Properties of Biomaterials Using PlasmaBased Technologies. Surface and Coatings Technology, 201, 8076-8082.

[8] Chu, P.K., Chen, J.Y., Wang, L.P. and Huang, N. (2002) Plasma-Surface Modification of Biomaterials. Materials Science and Engineering, 36, 143-206.

[9] Ma, Z., Mao, Z. and Gao, C. (2007) Surface Modification and Property Analysis of Biomedical Polymers Used for Tissue Engineering. Colloids and Surfaces B, 60, 137-157.

[10] Yorston, D. (2005) High-Volume Surgery in Developing Countries. Eye, 19, 10831089. https://doi.org/10.1038/sj.eye.6701966

[11] Ridley, N.H.L. (1951) Artificial Intraocular Lenses after Cataract Extraction. St Thomas Hospital Reports, 7, 12-14.

[12] Apple, D.J., Peng, Q., Arthur, S.N., Werner, L., Merritt, J.H., Vargas, L.G., Hoddinott, D.S.M., Escobar-Gomez, M. and Schmidbauer, J.M. (2002) Snowflake Degeneration of Polymethylmethacrylate Posterior Chamber Intraocular Lens Optic Material: A Newly Described Clinical Condition Caused by Unexpected Late Opacification of Polymethyl Methacrylate. Ophthalmology, 109, 1666-1675.

[13] Thanathanee, O., Ratanapakorn, T. and Suwan-Apichon, O. (2010) Postoperative Opacification of Polymethylmethacrylate Intraocular Lens. Asian Biomedicine, 4, 457-462.

[14] Gilmour, D.F., Taguri, A. and Bennett, H.G. (2003) Delayed Opacification of a PMMA Intraocular Lens. Journal of Cataract \& Refractive Surgery, 29, 413-414.

[15] García, A.J. (2011) Chapter 36-Surface Modification of Biomaterials. In: Atala, A., Lanza, R., Thomson, J.A. and Nerem, R., Eds., Principles of Regenerative Medicine, 2nd Edition, Academic Press, San Diego, 663-673.

[16] Ghatora, B.K., Barton, S.J., Foot, P.J.S. and Miller Tate, P. (2014) The Effect of Direct Gas Fluorination on Medical Grade Poly(methyl methacrylate). Open Journal of Organic Polymer Materials, 4, 74-83. https://doi.org/10.4236/ojopm.2014.44010

[17] Lagow, R.J. and Margrave, J.L. (1979) Direct Fluorination: A "New" Approach to 
Fluorine Chemistry. Progress in Inorganic Chemistry, 26, 161-210. https://doi.org/10.1002/9780470166277.ch3

[18] Papagni, A., Campiglio, P., Campione, M., Del Buttero, P., Mani, A., Miozzo, L. and Tonelli, E. (2008) Synthesis and Physical Properties of Polyfluoro-Acridines Bearing Perfluoroalkyl Chains. Journal of Fluorine Chemistry, 129, 294-300.

[19] Bianco, A., Iardino, G., Bertarelli, C., Miozzo, L., Papagni, A. and Zerbi, G. (2007) Modification of Surface Properties of Electrospun Polyamide Nanofibers by Means of a Perfluorinated Acridine. Applied Surface Science, 253, 8360-8364.

[20] Papagni, A., Del Buttero, P., Moret, M., Sassella, A., Miozzo, L. and Ridolfi, G. (2003) Synthesis and Properties of Some Derivatives of 1,2,3,4-Tetrafluoroacridine for Solid State Emitting Systems. Chemistry of Materials, 15, 5010-5018.

[21] Chirilaa, T.V., Morrison, D.A., Gridnevaa, Z., Meyrickb, D., Hicksa, C.R. and Webbb, J.M. (2005) Effect of Multipurpose Solutions for Contact Lens Care on the in Vitro Drug-Induced Spoliation of Poly(2-Hydroxyethyl Methacrylate) in Simulated Aqueous Humour. Contact Lens and Anterior Eye, 28, 21-28.

[22] Miller-Chou, B.A. and Koenig, J.L. (2003) A Review of Polymer Dissolution. Progress in Polymer Science, 28, 1223-1270.

[23] Crank, J. (1975) Mathematics of Diffusion. Oxford University Press, Oxford, 1-48.

\section{Submit or recommend next manuscript to SCIRP and we will provide best} service for you:

Accepting pre-submission inquiries through Email, Facebook, LinkedIn, Twitter, etc. A wide selection of journals (inclusive of 9 subjects, more than 200 journals)

Providing 24-hour high-quality service

User-friendly online submission system

Fair and swift peer-review system

Efficient typesetting and proofreading procedure

Display of the result of downloads and visits, as well as the number of cited articles

Maximum dissemination of your research work

Submit your manuscript at: http://papersubmission.scirp.org/

Or contact jbnb@scirp.org 